\title{
The impact of two modules on first year occupational therapy students' knowledge and attitudes to the core constructs of occupation
}

\author{
Caryn Green BSc O T (UCT)**
}

Kerry Hudson BSc O T (UCT)**

Minkateko Wicht BSc O T (UCT)**

Claire Willows BSc O T (UCT)**

Helen Buchanan BSc OT (UCT); MSc OT (UCT); PhD (UCT)

Senior Lecturer, Department of Health \& Rehabilitation Sciences, University of Cape Town

** 4th year Occupational therapy students at the University of Cape Town at the time the research was conducted.

Introduction: The first year occupational therapy course at the University of Cape Town focusses on developing an understanding of occupation. Two first semester modules form the foundation for this understanding. This study aimed to describe the impact of these modules on first year students' knowledge of, and attitudes towards, the core constructs of occupation.

Methodology: A pre-experimental one-group pre-test post-test design was used with a convenience sample recruited from the 2013 first year occupational therapy class. A self-administered questionnaire was developed for the study based on an extensive literature review and consultation with international occupational therapy experts. Data were gathered before and after participating in the modules. Content and construct validity, test-retest and inter-rater reliability were determined using the expert panel and a pilot test. Data were analysed with STATISTICA.

Results: Forty-five $(N=60)$ participants completed pre-test and post-test questionnaires and were included in the analysis. Knowledge improved significantly $(p<0.001)$ between pre-test and post-test, and positive attitudinal changes were noted.

Conclusion: Knowledge and attitudes improved after completing the modules suggesting that students were equipped with a sound foundational understanding of the core constructs of occupation.

Key words: Occupation; core constructs; knowledge; attitudes; education; occupational therapy

\section{INTRODUCTION}

Occupational therapy is a dynamic profession that continues to evolve and adapt depending on the culture and society in which it is practised. In the last 30 years there has been a global shift in the profession, from a focus on performance components to an occupation-based approach ${ }^{1,2}$. The University of Cape Town (UCT) Division of Occupational Therapy sought to align with these trends while continuing to develop an African orientation to the practice of occupational therapy. This decision necessitated an intense process of curriculum review, and, in 2009, a new undergraduate curriculum was introduced starting at first year level. The first year curriculum consists of two semester courses which focus on developing an understanding of occupation as central to the profession. The first semester course "... introduces students to the basic concepts that underlie occupational therapy principles, values and modes of practice" 3:46 and consists of four modules, two of which (Basic concepts of Human Occupation and Artforms) focus on occupation. The learning outcomes for these modules are shown in Appendix I.

Basic Concepts of Human Occupation exposes students to occupation and its constructs for the first time. Utilising a didactic teaching approach, the module provides a foundation for understanding occupation through exposure to several theorists but with particular emphasis on Nelson's conceptualisation of occupation ${ }^{4,5}$. Nelson ${ }^{4: 633}$ defines occupation as the “... relationship between occupational form (external circumstances) and occupational performance (the active behaviour)" and highlights active engagement in occupations within a specific context. Artforms, on the other hand, takes an experiential learning approach to consolidate the theoretical constructs from the Basic Concepts of Human Occupation module. An artform is understood as 'an activity or a piece of artistic work that can be regarded as a medium of artistic expression's. This module affords an opportunity to explore and experi- ence an artform as an occupation within two different contexts, using Nelson' ${ }^{4,5}$ constructs.

In 2013, the new first year curriculum was in its fifth year and the educators wished to evaluate its success in meeting its educational outcomes. This study therefore aimed to describe the impact of the Basic Concepts of Human Occupation and Artforms modules on knowledge and attitudes to the core constructs of occupation in first year students. The purpose of the research was firstly, to evaluate the modules and establish their effectiveness in meeting the learning outcomes, and secondly, to inform further development of the first year curriculum by identifying areas that were effective and those requiring revision.

\section{LITERATURE REVIEW}

Occupational therapy is founded upon a holistic approach to healthcare which aligns with the World Health Organization (WHO) definition of health as 'a state of complete physical, mental and social well-being and not merely the absence of disease or infirmity' 7 . The fundamental belief that occupation is a determinant of health informs practice which aims to enhance well-being through engagement in meaningful occupations ${ }^{8}$.

According to Kielhofner ${ }^{2}$, the profession has undergone two paradigm shifts. The first paradigm focused on occupation and the benefit of occupational engagement. The medical model influenced the second paradigm shift that took a more scientific, reductionist approach emphasising performance component remediation. Currently, within the third paradigm, the profession has returned to occupation with a more complex and holistic understanding of humans as occupational beings'. The current paradigm has enabled occupational therapists to realign their practice towards an occupation-based approach to enhance the health and wellbeing of individuals, groups and communities. 
Table I: Questionnaire details

\begin{tabular}{|c|c|c|c|c|}
\hline Section & Content & $\begin{array}{c}\text { Pre-test or } \\
\text { post-test }\end{array}$ & $\begin{array}{c}\text { Number of } \\
\text { questions }\end{array}$ & Type of question \\
\hline A & Demographic information & Both & 5 & $\begin{array}{c}\text { Closed questions (2 dichotomous with check } \\
\text { boxes) }\end{array}$ \\
\hline B & $\begin{array}{c}\text { Knowledge of Nelson's constructs of } \\
\text { occupation }\end{array}$ & Both & 6 & - I with a 3-point rating scale \\
\hline C & As above & Both & 9 & $\begin{array}{c}\text { - } 8 \text { multiple choice questions based on two } \\
\text { scenarios (4 questions per scenario) }\end{array}$ \\
\hline D & $\begin{array}{c}\text { Attitudes towards Nelson's } \\
\text { constructs of occupation }\end{array}$ & Both & 6 & $\begin{array}{c}\text { Likert Scales with additional space for comment } \\
\text { contitional space for }\end{array}$ \\
\cline { 2 - 5 } & $\begin{array}{c}\text { Attitudes to the content and } \\
\text { education methods used in the Basic } \\
\text { Concepts of Human Occupation and } \\
\text { Artforms modules }\end{array}$ & Post-test & 6 & As above \\
\hline
\end{tabular}

With the shift to an occupation-based approach, occupational therapy researchers have sought to understand the complexity of occupation and articulate its constructs clearly ${ }^{1,9}$. While different theorists understand the term 'occupation' from varying angles, all highlight similar aspects within their definitions, namely who is involved, where it takes place, what is done and how it is experienced. These aspects align with Nelson' ${ }^{4,5}$ constructs of occupation which he terms 'developmental structure', 'occupational form', 'occupational performance' and 'meaning'. However, ambiguity continues to surround the term 'occupation"10 which creates uncertainty about professional identity and blurs the boundaries between occupational therapy and other professions ${ }^{11,12}$. As students are particularly susceptible to this confusion, occupation-based practice should be emphasised in educational curricula to ensure the development of a strong professional identity and a sound understanding of the importance of occupation ${ }^{12}$. To this end, learning tasks to assist the exploration of occupation and its multiple constructs are introduced from first year to ensure that students develop the necessary knowledge, skills and attitudes required for practice. To this end, first year occupational therapy students at UCT are exposed to a variety of definitions and theories of occupation within the Basic Concepts of Human Occupation and Artforms modules, with an emphasis on Nelson's work. However, as Nelson argued that his conceptualisation of occupation aligns with that of other theorists ${ }^{5}$, it is possible that these modules may equip students with a broad understanding of occupation that allows them to explore their own conceptualisation of the constructs thereby shaping their professional identity.

\section{METHODOLOGY}

\section{Study design}

A pre-experimental one-group pre-test post-test design was employed.

\section{Participants}

The population comprised first year UCT occupational therapy students in $2013(N=60)$. Convenience sampling ensured the inclusion of as many participants as possible. The minimum sample size was calculated at 30 participants. This was based on estimated average pre-test and post-test knowledge scores (section B of the questionnaire) of $30 \%$ and $75 \%$ respectively, a standard deviation of $10 \%$ and a hypothesised average improvement of $45 \%$ (with $90 \%$ power and a 0.05 level of significance).

\section{Instrumentation}

As this was the first occupational therapy study of its kind, a questionnaire to evaluate knowledge and attitudes before and after exposure to the modules had to be developed. Given the time and resource constraints, a self-administered paper-based questionnaire was selected for its likelihood of producing a higher response rate ${ }^{13-15}$.

\section{Development of the questionnaire}

The process of questionnaire development included an extensive literature review, consultation with international occupational therapy experts, and a pilot test. Nelson's ${ }^{4,5}$ constructs were used to guide the content, and the questionnaire adhered to sound design principles in length ${ }^{16}$ and varying response formats ${ }^{17}$. Formats included multiple choice questions (MCQs), which produce efficient, reliable results, and allow comparison of performance levels ${ }^{18,19}$, dichotomous response options, and 5-point Likert Scales which are commonly used to assess attitudes ${ }^{20}$. Close- and open-ended questions were included to increase reliability and scoring consistency while producing individualised responses that allowed participants to elaborate ${ }^{18,21,22}$. Response bias was minimised by including positively and negatively worded statements that encouraged active engagement for accurate comprehension ${ }^{20}$.

The questionnaire consisted of four sections (see Table I above for a summary).

Demographic information in Section A included aspects such as age, gender and home language. Sections $B$ and $C$ evaluated knowledge of Nelson's ${ }^{4,5}$ conceptualisation of occupation and the core constructs of 'developmental structure', 'occupational form', 'occupational performance' and 'meaning' through open-ended questions and MCQs. The MCQs had a single-best answer and tested knowledge application by requiring participants to identify the core constructs of occupation within two short case studies. The case studies were structured on the outcomes of the Artforms module and entailed identifying aspects of occupational engagement in urban and informal contexts. This combination of case studies with single-best answer questions have been shown to be effective and reliable in assessing knowledge application from a first year leve $^{23}$. Section D contained questions related to attitudes towards the constructs of 'occupation' 'meaning', 'person' and 'environment'. Participants were asked to justify their answers to provide a deeper understanding of their responses ${ }^{19,24}$. Examples of questions in sections B to D are presented in Table II on page 65.

\section{Scoring the questionnaires}

Marking guides were developed for the study. The open-ended questions (section B) were scored with a rubric ${ }^{25}$ and the MCQs (sections $C$ and $D$ ) with a marking memorandum. The rubric contained four levels outlining the essential components for correctly defining each construct to enable raters to readily select the appropriate level for each response ${ }^{26}$. Levels were assigned a score from zero to four. A 'strong' response required a comprehensive description of each construct, whilst 'competent', 'basic competence' and 'weak' responses demonstrated lessening degrees of understanding. The levels provided an objective way to rate the open-ended responses, thus enhancing intra- and inter-rater reliability $(\mathrm{IRR})^{25}$. While the criteria for each level were primarily guided by Nelson ${ }^{4,5}$, other theorists' included in the lecture content were incorporated to 
Table II: Examples of questions in the questionnaire

Section B: Knowledge of the core constructs of occupation

\section{Examples:}

What is your understanding of 'occupation' as used by occupational therapists?

What is your understanding of 'developmental structure' (Nelson, 1988)?

\section{Section C: Knowledge of the core constructs of occupation}

In the following scenario, please tick the most appropriate answer to the questions.

\section{Scenario:}

$\mathrm{Mr} J$ is a 53 year old man who makes traditional Xhosa clay pots with the help of his son. They make these in his informal dwelling in the township of Khayelitsha. Mr J sells these to tourists and this is his family's only source of income. As he is able to provide for his family Mr J feels in touch with his role as a man.

\section{Please select the single best answer.}

What is the 'developmental structure' in this scenario?
$\square$ a) The presence of Mr J's son
$\square$ b) His informal dwelling in Khayelitsha
$\square$ c) Mr J
$\square \quad$ d) Making the clay pots
$\square$ e) Influence of Xhosa tradition

Please select up to three of the options that best answer/answers the question.

What is the 'occupational form' in this scenario?
$\square$ a) Mr J feels in touch with his role as a man
b) The presence of Mr J's son
$\square$ c) MrJ
$\square$ d) His informal dwelling in Khayelitsha
$\square$ e) 53 years old
$\square$ f) Influence of Xhosa tradition
$\square$ g) Making the clay pots

Do you think that the environment plays a role in how Miss $\mathrm{K}$ and $\mathrm{Mr} J$ do pottery?

Yes: $\square \quad$ No: $\square$

Give a reason for your answer.

\section{D: Attitudes}

Please tick the option which best describes your attitude towards the following statements and give a reason for your choice.

Please read carefully.

I feel that a person's skills, abilities and roles influence what they do.

Strongly disagree $\square \quad$ Disagree $\square \quad$ Neutral $\square \quad$ Agree $\square \quad$ Strongly agree $\square$

Give a reason for choice:

I think that a person's culture will not influence what they do.

Strongly disagree $\square \quad$ Disagree $\square \quad$ Neutra $\square \quad$ Agree $\square \quad$ Strongly agree $\square$

Give a reason for your choice:

Post-test questionnaire only

Section D: Attitudes to occupation and the teaching methods used in the modules

Since completing the Human Occupation and Art Forms modules, I have a greater appreciation of occupation.

Strongly disagree $\square \quad$ Disagree $\square \quad$ Neutral $\square \quad$ Agree $\square \quad$ Strongly agree $\square$

Give a reason for your choice:

I find group work an effective tool for learning.

Strongly disagree $\square \quad$ Disagree $\square \quad$ Neutral $\square \quad$ Agree $\square \quad$ Strongly agree $\square$

Give a reason for your choice:

ensure that participants were not penalised if they demonstrated an understanding of the constructs but did not draw on Nelson's exact definitions. The marking memorandum listed the correct answers for the MCQs (Section C) and desired responses for Likert scale items (Section $\mathrm{D})^{25}$. Desired responses for attitude questions were based on the perspectives and values regarding the relationship between occupation and its core constructs within the profession.

\section{Pilot test}

A pilot test to assess test-retest reliability, face validity and utility of the questionnaire, and identify and resolve errors within the marking rubric, was conducted with 12 second year occupational therapy students prior to data collection. Participants completed the questionnaire on the agreed date and again two days later. The administration procedure of the pilot test mirrored that of the main 
study. Questionnaires were completed under test conditions and participants were asked not to discuss or research their responses to the pre-test until they had completed the post-test. After the post-test, participants engaged in a structured discussion to share their views about the length, format, wording, and ease of completing the questionnaire ${ }^{27,28}$. Feedback from the pilot study resulted in the following changes to the questionnaire:

* Wording of particular questions was simplified and MCQ response options adjusted to improve clarity;

- Negatively worded statements in Section D were written in bold to make them more noticeable, and an instruction added to 'read the questions carefully';

* Formatting was changed to allow sufficient space for responses and to improve the readability of the questionnaire.

\section{Validity and reliability}

\section{Questionnaire}

The questionnaire was sent to a panel of seven occupational therapy experts to evaluate its content and construct validity. Panel members were chosen for their acknowledged expertise within the profession based on their publications and research in the area of human occupation. The panel indicated that 'developmental structure'4 should be included in sections $B$ and $C$ and 'occupational form' should be expanded in section $C$ to include all aspects of the environment, rather than focussing purely on the physical component. This feedback was used to revise the questionnaire. The questionnaire is available on request.

\section{Marking guides}

Pilot test questionnaires were marked independently by two raters using the first draft of the rubric. Issues relating to the comprehensiveness of the rubric and ease of marking during this process necessitated some revisions to the rubric (draft 2), which were discussed with the research supervisors and revised further (draft 3). Pilot questionnaires were re-marked using draft 3. Feedback from this process led to the development of draft 4 of the rubric which was sent to two members of the expert panel for input. Their feedback was used to further refine the rubric and to re-mark the pilot questionnaires. The marking guides are available from the authors on request.

Test-retest reliability using data from the first and second pilot tests revealed that agreement for Section B was satisfactory ("good" to "excellent" for questions I - 4 (ICC=0.604-0.879), and "fair to moderate" for question $5(\mathrm{ICC}=0.566))^{29}$. Test-retest reliability for Sections $C$ and $D$ was less than satisfactory however ("poor" to "substantial" for section C (Kappa: -0.13; 0.63) and "poor" to "almost perfect" for section D (Kappa: $-0.09 ; 0.82))^{30}$. To determine the IRR of the marking guides, two raters independently marked the pilot study questionnaires with the final rubric and marking memorandum. IRR for Sections B (ICC=0.760-0.950), C and $D$ (Kappa: I.0 respectively) was excellent ${ }^{29,30}$.

\section{Data collection procedure}

The pre-test was conducted at the end of the first lecture of the Basic Concepts of Human Occupation module. The post-test was administered three months later, on completion of the Basic Concepts of Human Occupation and Artforms modules. The three month time-span between tests along with changes in the ordering of the $\mathrm{MCQ}$ response options for the post-test, assisted in reducing the practice effect ${ }^{3 !}$. The same questionnaire was used for the pre- and post-tests except that six questions covering attitudes to the content and the teaching methods employed in the modules were added (these are not reported in this article). Pre-tests and post-tests were administered in a maximum time of 30 minutes and under the same conditions to reduce respondent error ${ }^{32}$. Questionnaires were marked independently by two raters with the final marking guides. Any discrepancies were discussed and consensus reached on the final scores.

\section{Data management and analysis}

Each participant received a numbered questionnaire which cor- responded to their number on the list of participants for tracking purposes. Data were entered into STATISTICA ${ }^{\mathrm{TM}}$ immediately after data collection and double checked to ensure accuracy. Electronic data were password protected and encrypted to allow access by the researchers only.

Analysis was conducted with STATISTICA ${ }^{\mathrm{TM}}$. As numerical data were not normally distributed, medians and ranges were calculated. Frequencies and proportions were determined for all categorical data. Responses to open-ended questions were analysed post-hoc ${ }^{33}$ and frequencies and proportions calculated for each category and theme. Changes in Section B (questions I to 5) knowledge scores from pre-test to post-test were compared with Wilcoxon's matched pairs test. McNemar's test was used to detect significant differences for Section $C$ knowledge items between pre-test and post-test.

\section{Ethics}

Ethical approval was obtained from the UCT Human Research Ethics Committee (HREC ref: 020/20I3). Informed consent was obtained from participants prior to data collection.

\section{RESULTS}

Fifty-eight participants $(\mathrm{N}=60)$ completed the pre-test and 45 completed the post-test (see Figure I for the study flow diagram). Only data for participants who completed both tests $(n=45)$ were analysed; this represented $75 \%$ of the population. There were 39 females and six males with a median age of I8.0 (range: I7.0, 27.0) years. English was the home language of 26 participants $(57.8 \%)$. Twenty-five participants (55.6\%) had chosen occupational therapy as their first choice of study.

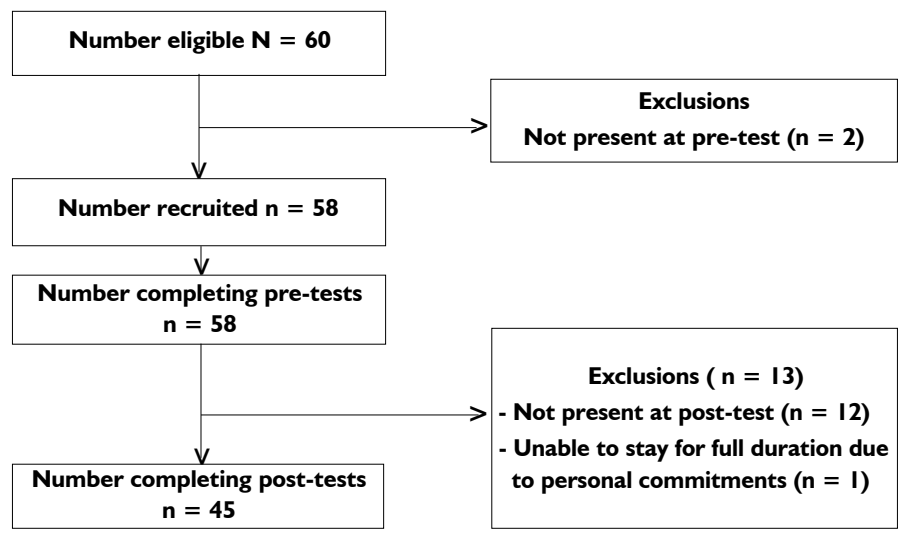

Figure I: Flow diagram of participants

\section{Knowledge}

Knowledge increased significantly $(p<0.00 \mathrm{I})$ between pre-test and post-test for all Section B questions except question $4(p=0.073)$ (see Table III on page 67).

Similarly, there was a significant increase in knowledge scores in Section $C$ from pre-test to post-test for all questions except question 4.3 for both scenarios (What is the 'occupational form' in this scenario? (Cultural) and question 2 for scenario 2 (What is the 'occupational performance' in this scenario?) (see Table IV on page 67).

\section{Attitudes}

Positive attitudinal changes occurred between pre-test and posttest as shown by the increased number of participants selecting the desired response option for each question at the post-test (see Table $V$ on page 67 - increases shown in bold).

Themes emerging from the analysis of the open-ended questions for questions I I ('I feel that the environment does not play a significant role in what a person does') and I 2 ('I feel that occupation is an important part of life') give additional insights into participants understanding of the core constructs of occupation (see Tables VI and VII on page 68). 
Table III: Knowledge scores for Section B $(n=45)$

\begin{tabular}{|c|c|c|c|c|c|c|}
\hline \multirow[b]{2}{*}{ Question (possible score) } & \multicolumn{2}{|c|}{ Pre-test } & \multicolumn{2}{|c|}{ Post-test } & \multicolumn{2}{|c|}{ Wilcoxon matched pairs test } \\
\hline & $\begin{array}{l}\text { Median } \\
\text { (Range) }\end{array}$ & $\begin{array}{c}\text { Missing } \\
\text { responses } \\
\text { n (\%) }\end{array}$ & $\begin{array}{l}\text { Median } \\
\text { (Range) }\end{array}$ & $\begin{array}{c}\text { Missing } \\
\text { responses } \\
\text { n (\%) }\end{array}$ & $\begin{array}{c}\mathbf{T} \\
(\mathbf{Z})\end{array}$ & p-value \\
\hline $\begin{array}{l}\text { I. What is your understanding of 'occupation' } \\
\text { as used by occupational therapists? }\end{array}$ & $\begin{array}{c}2.0 \\
(0.0,3.0)^{*}\end{array}$ & $\begin{array}{c}0 \\
(0.0)\end{array}$ & $\begin{array}{c}3.0 \\
(2.0,4.0)^{*}\end{array}$ & $\begin{array}{c}0 \\
(0.0) \\
\end{array}$ & $10.5(4.38)$ & $<0.001$ \\
\hline $\begin{array}{l}\text { 2. What is your understanding of } \\
\text { 'developmental structure'? }\end{array}$ & $\begin{array}{c}0.0 \\
(0.0,3.0)\end{array}$ & $\begin{array}{c}12 \\
(26.7)\end{array}$ & $\begin{array}{c}2.0 \\
(0.0,3.0)\end{array}$ & $\begin{array}{c}0 \\
(0.0)\end{array}$ & $\begin{array}{c}32.5 \\
(3.76)\end{array}$ & $<0.001$ \\
\hline $\begin{array}{l}\text { 3. What is your understanding of } \\
\text { 'occupational form'? }\end{array}$ & $\begin{array}{c}0.0 \\
(0.0,1.0)\end{array}$ & $\begin{array}{c}15 \\
(33.3)\end{array}$ & $\begin{array}{c}2.0 \\
(0.0,4.0)\end{array}$ & $\begin{array}{c}0 \\
(0.0)\end{array}$ & $\begin{array}{c}0.0 \\
(5.23)\end{array}$ & $<0.001$ \\
\hline $\begin{array}{l}\text { 4. What is your understanding of } \\
\text { 'occupational performance'? }\end{array}$ & $\begin{array}{c}2.0 \\
(0.0,2.0)\end{array}$ & $\begin{array}{c}9 \\
(20.0)\end{array}$ & $\begin{array}{c}1.0 \\
(0.0,3.0)\end{array}$ & $\begin{array}{c}0 \\
(0.0)\end{array}$ & $\begin{array}{l}168.0 \\
(1.80)\end{array}$ & 0.073 \\
\hline $\begin{array}{l}\text { 5. What is your understanding of 'meaning' } \\
\text { with regards to occupation? }\end{array}$ & $\begin{array}{l}0.0 \\
(0.0,2.0)\end{array}$ & $\begin{array}{c}15 \\
(33.3)\end{array}$ & $\begin{array}{c}1.0 \\
(0.0,3.0)\end{array}$ & $\begin{array}{c}1 \\
(2.2)\end{array}$ & $\begin{array}{c}10.0 \\
(4.83)\end{array}$ & $<0.001$ \\
\hline
\end{tabular}

Table IV: Correct responses to knowledge questions in section C (MCQs) $(n=45)$

\begin{tabular}{|c|c|c|c|c|c|c|}
\hline \multirow[t]{3}{*}{ Question } & \multicolumn{3}{|c|}{ Scenario I } & \multicolumn{3}{|c|}{ Scenario 2} \\
\hline & \multirow{2}{*}{\begin{tabular}{c|} 
Pre-test \\
n (\%)
\end{tabular}} & \multirow{2}{*}{$\begin{array}{c}\text { Post-test } \\
\text { n (\%) }\end{array}$} & \multirow{2}{*}{$\begin{array}{l}\text { McNemar } \\
\text { p-value }\end{array}$} & \multirow{2}{*}{$\begin{array}{c}\text { Pre-test } \\
\text { n (\%) }\end{array}$} & \multirow{2}{*}{$\begin{array}{c}\text { Pre-test } \\
\text { n (\%) }\end{array}$} & \multirow{2}{*}{$\begin{array}{l}\text { McNemar } \\
\text { p-value }\end{array}$} \\
\hline & & & & & & \\
\hline $\begin{array}{l}\text { I. What is the 'developmental } \\
\text { structure' in this scenario? }\end{array}$ & $2(4.4)$ & $16(35.6)$ & $<0.001$ & $2(4.4)$ & $16(35.6)$ & $<0.001$ \\
\hline $\begin{array}{l}\text { 2. What is the 'occupational } \\
\text { performance' of Miss } \mathrm{K} / \mathrm{Mr} \text { J in this } \\
\text { scenario? }\end{array}$ & $31(68.9)$ & $42(93.3)$ & 0.008 & $33(73.3)$ & 40 (88.9) & 0.071 \\
\hline $\begin{array}{l}\text { 3. What is the 'meaning' Miss } \mathrm{K} / \mathrm{Mr} \\
\text { J obtains from doing pottery? }\end{array}$ & $4 I$ (9I.I) & $45(100.0)$ & 0.046 & $4 I$ (9I.I) & $45(100.0)$ & 0.046 \\
\hline $\begin{array}{l}\text { 4.I What is the 'occupational form' } \\
\text { in this scenario? (Physical)" }\end{array}$ & $12(26.7)$ & $29(64.4)$ & $<0.001$ & $16(35.6)$ & 32 (7I.I) & $<0.001$ \\
\hline $\begin{array}{l}4.2 \text { What is the 'occupational form' } \\
\text { in this scenario? (Social)" }\end{array}$ & $14(31.1)$ & $26(57.8)$ & 0.005 & $16(35.6)$ & $26(57.8)$ & $0.04 I$ \\
\hline $\begin{array}{l}4.3 \text { What is the 'occupational form' } \\
\text { in this scenario? (Cultural)" }\end{array}$ & $16(35.6)$ & $22(48.9)$ & 0.201 & $18(40.0)$ & $22(48.9)$ & 0.394 \\
\hline
\end{tabular}

Table V: Responses to attitude questions (Section D) at pre-test and post-test $(n=45)$

\begin{tabular}{|c|c|c|}
\hline \multirow[t]{2}{*}{ Question } & Baseline & Final \\
\hline & No. (\%) & No. (\%) \\
\hline \multicolumn{3}{|c|}{ 10. I feel that a person's skills, abilities and roles influence what they do } \\
\hline Strongly Disagree & $\mathrm{I}(2.2)$ & $\mathrm{I}(2.2)$ \\
\hline Disagree & $0(0.0)$ & $\mathrm{I}(2.2)$ \\
\hline Neutral & $3(6.7)$ & $0(0.0)$ \\
\hline Agree & $19(42.2)$ & $12(26.7)$ \\
\hline Strongly Agree* & $18(40.0)$ & $27(60.0)$ \\
\hline Excluded $^{* *}$ & $4(8.9)$ & $4(8.9)$ \\
\hline \multicolumn{3}{|c|}{ I I. I feel that the environment does not play a significant role in what a person does } \\
\hline Strongly Disagree* & $13(28.9)$ & $24(53.3)$ \\
\hline Disagree & $21(46.7)$ & $17(37.8)$ \\
\hline Neutral & $6(13.3)$ & $2(4.4)$ \\
\hline Agree & $\mathrm{I}(2.2)$ & $0(0.0)$ \\
\hline Strongly Agree & $\mathrm{I}(2.2)$ & $\mathrm{I}(2.2)$ \\
\hline Excluded** & $3(6.7)$ & $\mathrm{I}(2.2)$ \\
\hline \multicolumn{3}{|c|}{ 12. I feel that occupation is an important part of life } \\
\hline Strongly Disagree & $0(0.0)$ & $0(0.0)$ \\
\hline
\end{tabular}


...Table $\mathrm{V}$ continued from page 67

\begin{tabular}{|c|c|c|}
\hline Disagree & $0(0.0)$ & $0(0.0)$ \\
\hline Neutral & $3(6.7)$ & I (2.2) \\
\hline Agree & $12(26.7)$ & II (24.4) \\
\hline Strongly Agree* & $26(57.8)$ & 32 (7I.1) \\
\hline Excluded ${ }^{* *}$ & $4(8.9)$ & I (2.2) \\
\hline \multicolumn{3}{|c|}{ 13. I feel that meaning is a subjective experience } \\
\hline Strongly Disagree & $\mathrm{I}(2.2)$ & I (2.2) \\
\hline Disagree & $\mathrm{I}(2.2)$ & $0(0.0)$ \\
\hline Neutral & $17(37.8)$ & $5(11.1)$ \\
\hline Agree & $7(15.6)$ & $9(20.0)$ \\
\hline Strongly Agree* & $14(31.1)$ & $28(62.2)$ \\
\hline Missing & $5(I I . I)$ & $2(4.4)$ \\
\hline \multicolumn{3}{|c|}{ 14. I feel that meaning influences what a person does } \\
\hline Strongly Disagree & $\mathrm{I}(2.2)$ & $0(0.0)$ \\
\hline Disagree & $I(2.2)$ & $0(0.0)$ \\
\hline Neutral & $8(17.8)$ & I (2.2) \\
\hline Agree & $22(48.9)$ & $18(40.0)$ \\
\hline Strongly Agree* & $9(20.0)$ & $26(57.8)$ \\
\hline Missing & $4(8.9)$ & $0(0.0)$ \\
\hline \multicolumn{3}{|c|}{ I5. I think that a person's culture will not influence what they do } \\
\hline Strongly Disagree* & $15(33.3)$ & 21 (46.7) \\
\hline Disagree & $19(42.2)$ & $17(37.8)$ \\
\hline Neutral & $6(13.3)$ & $5(11.1)$ \\
\hline Agree & $2(4.4)$ & $0(0.0)$ \\
\hline Strongly Agree & I (2.2) & I (2.2) \\
\hline Excluded ${ }^{* *}$ & $2(4.4)$ & I (2.2) \\
\hline
\end{tabular}

Table VI: Themes for 'I feel that the environment does not play a significant role in what a person does' (question I I)

\begin{tabular}{|c|c|c|c|}
\hline Themes & Categories & $\begin{array}{c}\text { Pre-test }[N=40]: \\
n(\%)\end{array}$ & $\begin{array}{c}\text { Post-test }[\mathrm{N}=44]: \\
n(\%)\end{array}$ \\
\hline The environment influences occupational performance & & $15(37.5)$ & $23(52.3)$ \\
\hline Environment can be a barrier or support for occupational performance & & $7(17.5)$ & $23(52.3)$ \\
\hline \multirow{6}{*}{ Environment influences developmental structure } & Generally & I (2.5) & $5(11.4)$ \\
\hline & Human development & $6(15.0)$ & $\mathrm{I}(2.3)$ \\
\hline & Decision-making & $6(15.0)$ & $3(6.8)$ \\
\hline & Beliefs \& Perceptions & $2(5.0)$ & $\mathrm{I}(2.3)$ \\
\hline & Thought processes & I (2.5) & - \\
\hline & Values and morals & - & I (2.3) \\
\hline People can control how the environment shapes them & & $3(7.5)$ & I (2.3) \\
\hline
\end{tabular}

Table VII: Themes for 'I feel that occupation is an important part of life' (question I2)

\begin{tabular}{|l|l|c|c|}
\hline \multicolumn{1}{|c|}{ Themes } & Categories & $\begin{array}{c}\text { Pre-test [N=37]: } \\
\mathbf{n}(\%)\end{array}$ & $\begin{array}{c}\text { Post-test [N=44]: } \\
\mathbf{n}(\%)\end{array}$ \\
\hline Occupation provides meaning & & $6(16.2)$ & $22(50.0)$ \\
\hline Occupation involves everything one does & & $15(40.5)$ & $20(45.5)$ \\
\hline Occupation influences who one is as a holistic being & & $16(43.2)$ & $12(27.3)$ \\
\hline \multirow{2}{*}{ Occupation influences developmental structure } & Interpersonal skills & $2(5.4)$ & $2(4.5)$ \\
\cline { 2 - 4 } & Decision-making & $2(5.4)$ & $2(4.5)$ \\
\cline { 2 - 4 } & Capabilities & $1(2.7)$ & - \\
\hline
\end{tabular}




\begin{tabular}{|c|c|c|c|}
\hline \multirow{3}{*}{ Occupation influences developmental structure } & Self-esteem & $\mathrm{I}(2.7)$ & $\mathrm{I}(2.3)$ \\
\hline & Emotional state & I (2.7) & $3(6.8)$ \\
\hline & Identity & - & $3(6.8)$ \\
\hline Purpose is determined by occupation & & $4(10.8)$ & $7(15.8)$ \\
\hline Occupations are unique in nature & & $3(8.1)$ & - \\
\hline
\end{tabular}

\section{DISCUSSION}

The study results indicate that the Basic Concepts of Human Occupation and Artforms modules were successful in meeting the learning outcomes of the first year course. Significant improvements in knowledge of the core constructs occurred with attitudinal shifts towards a greater appreciation of occupation and its dimensions. Participants' justifications for their responses to the attitude questions revealed impressive depth and understanding for this stage of their course. Changes in knowledge and attitudes for each construct are discussed further in separate sub-sections.

\section{Occupation}

Occupation is a complex term and challenging to define ${ }^{1,9}$. The marking rubric required participants to provide a comprehensive definition of occupation by highlighting its four constructs. It was encouraging that participants were able to draw from a variety of theorists to explain their understanding of occupation. Despite being in their first year, the majority of participants understood that occupations involve engagement in an activity by an individual. A greater understanding of 'meaning' as an integral part of occupation was also seen at post-test. Understanding of the role of 'occupational form' was however limited, as only fourteen participations utilised this construct to define 'occupation' in the post-test. Considering the learning outcomes of these modules, teaching related to the relationship between the environment and the occupation should be strengthened as this is crucial for developing a holistic understanding of occupation ${ }^{34}$.

Participants' attitudes towards occupation deepened by the end of the first semester. Most already displayed a sound appreciation of the importance of occupation within everyday life at the pre-test, and by the post-test, were able to link 'occupation' and 'meaning' while appreciating the centrality of occupations within daily life. Many of the themes emerging from the open-ended questions aligned directly with the philosophy underpinning the profession that occupations are an integral part of life ${ }^{1,2,35}$.

\section{Developmental Structure}

While significant increases in the knowledge scores for 'developmental structure' were observed at the end of the modules, the low scores for the open-ended questions and MCQs suggest that this construct was not well understood. Examination of participants' responses indicated that while they understood the construct of 'person or doer', they seemed to have limited understanding of this as 'developmental structure' as described by Nelson. When 'person' instead of 'developmental structure' was used in the attitude questions, many participants were able to highlight the influence of various aspects within the person (for example, personal capacities, knowledge and emotional state) on occupational performance. Thus it seems that the term 'person' was better understood than 'developmental structure'.

Participants' were able to highlight how competence shapes occupational choices and experiences, showing a clear alignment between their attitudes and the knowledge component of the modules. Participants' growing appreciation of the role of the 'person' within the occupation serves as a strong basis for further exploring the therapeutic value of occupations and how these can be tailored for different people to shape their development.

\section{Occupational Form}

The definition of 'occupational form' used in the rubric drew on an understanding of several theorists ${ }^{1,2,4,5,34}$. While the results indicate that understanding improved significantly, participants displayed only a basic knowledge of this construct at the post-test. However, due to the comprehensiveness of the highest level of response, participants were not expected to achieve maximum scores at this level of study.

Although there was an increase in understanding of the physi$\mathrm{cal}$ and social components of 'occupational form', knowledge of the cultural component was limited as seen by the small number of students who included culture in their open-ended responses in Section B, and who identified the cultural component of the occupational form in Section C. A basic understanding of culture within occupation is necessary to developing cultural competence which is essential for practice within a multicultural society such as South Africal, ${ }^{1,}$.

With regard to attitudes, the common theme 'environment influences occupational performance' that emerged at the pre-test and post-test revealed that students had an appreciation of the role of occupational form in 'doing'. Their attitudes also focused on the way in which the environment influences 'developmental structure', by identifying decision-making and thought processes as aspects of the person that may be influenced by the environment. This appreciation of 'occupational form' may have been influenced by the Artforms module in which students experienced the impact of different contexts on occupational performance. It is encouraging to note that at this stage in their education, students were beginning to grapple with the influence of occupational form, and its various dimensions, on occupation.

\section{Occupational Performance}

At the post-test, most participants only utilised the 'doing' aspect to describe 'occupational performance' and failed to include the 'person' and 'context' in their responses. This resulted in participants being penalised for not explicitly stating the criteria outlined in the rubric, and thus the lower marks in the post-test may not have been a true reflection of the change in participants' understanding, but rather due to their choice of wording.

It was interesting to note at the post-test that few participants made reference to the role of the environment in 'occupational performance', and that there was a decrease in the number of participants including the 'person' in their answers. This may suggest that the modules may not be explicitly highlighting the transactional relationship between occupation, person and environment resulting in an incomplete understanding of 'occupational performance'. It is important for students to grasp that 'doing' is the combination of an individual or group actively engaging in an occupation within a particular context as this will influence how they engage with clients and how they adapt the task or environment to suit the person.

Occupational performance is focussed on in the second semester.

\section{Meaning}

The number of participants demonstrating the desired attitude towards 'meaning' (Section D) increased from pre-test to posttest suggesting that students developed a greater appreciation of 'meaning' as a key construct of occupation ${ }^{36}$. The findings suggested, however that they had not yet developed a comprehensive understanding of this construct at the post-test. Christiansen ${ }^{36} \mathrm{em}$ phasised the importance of 'meaning' within occupational therapy but recognised that understanding the process of meaning-making is a long-term endeavour. First year students' cannot therefore be expected to fully comprehend the multiple aspects of this construct, but the subsequent years of study should ensure that students are given further opportunities to develop their understanding of meaning within occupational therapy. 


\section{Strengths and limitations}

The sample size represented $75 \%$ of the population which exceeded the minimum sample required. As a result the study findings can be generalised to the population of first year students at UCT in 20I3. The research design quantified the students' knowledge and attitudes and compared these before and after their engagement in the modules. This has provided some evidence of the impact of these modules in meeting the first year learning outcomes. Using a purely quantitative methodology, however, limited the depth of data gathered, particularly with regard to attitudes. As a result, more emphasis was placed on knowledge. As a control group could not be used, confounding variables, such as participants' self-directed learning and lecture attendance, may have influenced the results. The timing of the pre-test after the first Human Occupation lecture, and the practice effect, may also have confounded the results.

Although the questionnaire was designed for the study and underwent an extensive review process, limitations in its development and use may have negatively influenced the accuracy of the results. Time constraints did not permit piloting of the final questionnaire and therefore it is not known whether the test-retest reliability for section $C$ improved after revisions were made following the pilot study. The use of multiple choice questions limited the ability of the questionnaire to capture the complexity of occupation as it reduced the correct response to a single best answer ${ }^{17,37}$. Some questions were leading in nature, and responses may therefore not have been a true reflection of participants' knowledge and attitudes ${ }^{37}$. A further concern arose during the marking process, where the expectancy effect ${ }^{38}$ may have influenced the reliability of scores assigned by raters. The rubric may have had an influence on the study results as the educational outcomes only required students to display a basic understanding of occupation and its constructs, but the rubric required comprehensive responses which may have placed students at a disadvantage. Furthermore, while other theorists' understanding and definitions of constructs were incorporated into the rubric, placing such strong emphasis on Nelson's understanding may have disadvantaged students who preferred to use other theorists.

\section{CONCLUSION}

The study revealed a significant increase in knowledge of the core constructs of occupation, and a slight shift in attitudes by the end of the two modules. Although improvements in knowledge were apparent for most constructs, there were some gaps in understanding. These included the role of the environment within occupation, the cultural component of 'occupational form' as an integral part of the environment, and 'developmental structure' as relating to the person. Appropriate to their level of study, participants could describe 'occupational performance' and 'meaning' reflecting a basic understanding of these constructs. It is anticipated that as students' progress through the course, they will be provided with further opportunities to engage with the core constructs and develop a more comprehensive understanding of occupation. Assessing attitudinal changes over such a short period is very difficult, particularly with complex concepts. Attitudes did, however, appear to be aligned with the work of various occupational therapy theorists.

With the increased emphasis on the core constructs of occupation within the Minimum Standards for the Training of Occupational Therapists ${ }^{39}$, it was encouraging to note that within the first few months of their course, the first year occupational therapy students at UCT had the necessary understanding of an occupation-based approach to occupational therapy.

\section{RECOMMENDATIONS}

\section{Recommendations for education}

For first year students to develop a holistic understanding of occupation some aspects of the current course content should be strengthened. Firstly, students should be familiarised with the terminology relating to Nelson's conceptualisation of occupation. Secondly, greater emphasis should be placed on the role of the environment within occupation with further explanation and clarification of culture as an environmental component. Thirdly, opportunities should be provided for further discovery of how 'occupation' and 'occupational form' influence each other, and the impact they may have on occupational engagement. Lastly, students should be assisted in exploring the transactional relationships between the occupation, the person and the environment, and to grapple with the influences that these may have on occupational performance. To this end, the emphasis in teaching and learning activities should be placed on ensuring students understand and become confident in describing and applying concepts related to human occupation within a variety of contexts.

\section{Recommendations for research}

Future studies should take a mixed methods approach to capture students' learning experiences more fully while obtaining objective data to measure changes in knowledge and attitudes. The questionnaire and marking guides (rubric and memorandum) need to be reviewed and undergo further testing and validation to improve their validity and reliability. Once the questionnaire and marking guides have been strengthened, they should be used in a further study to re-assess the impact of the Basic Concepts of Human Occupation and Artforms modules. Such a study will provide evidence for the effectiveness of these two modules in meeting the first year learning outcomes and inform curriculum improvement.

\section{REFERENCES}

I. Hagedorn R. Occupational therapy: perspectives and processes. London: Churchill Livingstone, 1995.

2. Kielhofner G. Conceptual foundations of occupational therapy practice, 4th ed. Philadephia: FA Davis Company, 2009.

3. Division of Occupational Therapy University of Cape Town. Selfreview report for Health Professions Council of South Africa (HPCSA) Evaluation: 2012.

4. Nelson D. Occupation: Form and Performance. American Journal of Occupational Therapy. 1988; 42: 633-4I.

5. Nelson D. Therapeutic Occupation: A Definition. American Journal of Occupational Therapy. 1996; 50: 775-82.

6. Oxford Dictionaries. Oxford University Press, 2014.

7. Grad F. The Preamble of the Constitution of the World Health Organization. Bulletin of the World Health Organisation. 2002; 80: 982.

8. Law M, Steinwender S and Leclair L. Occupation, health, and wellbeing. Canadian Journal of Occupational Therapy. 1998; 65: 81-91.

9. Royeen C. Occupation reconsidered. Occupational Therapy International. 2002; 9: I I I-20.

10. Wu C and Lin K. Defining occupation: A comparative analysis. Journal of Occupational Science. 1999; 6: 5-12.

I I. Pierce D. Untangling occupation and activity. American Journal of Occupational Therapy. 2001; 55: 138-46.

12. Ikiugu $M$ and Rosso $H$. Facilitating professional identity in occupational therapy students. Occupational Therapy International. 2003; I0: 206-25.

13. Bowling A. Mode of questionnaire administration can have serious effects on data quality. Journal of Public Health. 2005; 27: 28I-9I.

14. Kaplan R, Sieber W and Ganiats T. The quality of well-being scale: Comparison of the interviewer-administered version with a self administered questionnaire. Psychology and Health. 1997; I2: 783-91.

15. Wright D, Aquilino W and Supple AJ. A comparison of computerassisted and paper-and-pencil self-administered questionnaires in a survey on smoking, alcohol, and drug use. Public Opinion Quarterly. 1998; 62: 331-53.

16. Sahlqvist S, Song Y, Bull F, Adams E, Preston J and Ogilvie D. Effect of questionnaire length, personalisation and reminder type on response rate to a complex postal survey: randomised controlled trial. BMC Medical Research Methodology. 20 I I; I I: I-8.

I7. Gendall $P$ and Hoek J. A question of wording. Marketing Bulletin 1990; I: 25-36.

18. Centre for Teaching and Learning. Improving multiple choice questions. Centre for Teaching and Learning. 1990; 8: I-4 (accessed August 20, 2013).

19. Momin Mujeeb A, Pardeshi M and Ghongane B. Comparative assessment of multiple choice questions versus short essay questions in pharmacology examinations. Indian Journal of Medical Science. 2010; 64: I I8-24. 
20. Croasmun J and Ostrom L. Using Likert-type scales in the social sciences. Journal of Adult Education. 201 I; 40: 19-22.

21. Funk $S$ and Dickson L. Multiple choice and short-answer exam performance in a college classroom. Teaching of Psychology. 201 I; 38: 273-7.

22. Palmer $E$ and Devitt P. Assessment of higher order cognitive skills in undergraduate education: modified essay or multiple choice questions? BMC Medical Education. 2007; 7: I-7.

23. National Board of Medical Examiners. Constructing written test questions for the basic and clinical sciences, 3rd ed. Philadelphia, USA: National Board of Medical Examiners, 2002.

24. Reja U, Manfreda K, Hlebec V and Vehovarl V. Open-ended vs. close-ended questions in web questionnaires. Developments in Applied Statistics. 2003; 19: 159-77.

25. Allen $D$ and Tanner K. Rubrics: Tools for making learning goals and evaluation criteria explicit for both teachers and learners. $\underline{C B E}$ Life Science Education. 2006; 5: 197-203.

26. Luft J. Design your own rubric. Science Scope. 1997; 20: 25-7.

27. Radhakrishna RB. Tips for developing and testing questionnaires/ instruments. Journal of Extension. 2007; 45: accessed 04 February 20I3).

28. Taylor-Powell E. "Pilot test your questionnaire." n.d. < https:// www.team-psa.com/brfss/2012/pres/K_Trepanier_questionnaire. pdf $>$ (23 October 2014.

29. Cicchetti $D$ and Sparrow SA. Developing criteria for establishing interrater reliability of specific items. American Journal of Mental Deficiency. 1981; 86: 127-37.

30. Landis J and Koch $\mathrm{G}$. The measurement of observer agreement for categorical data. Biometrics. 1977; 33: 159-74.

31. Falleti M, Maruff P, Collie A and Darby D. Practice effects associated with the repeated assessment of cognitive function using the CogState battery at I0-minute, one week and one month test-retest intervals. Journal of Clinical and Experimental Neuropsychology. 2006; 28: 1095-II 2.

32. Fecso R and Pafford $B$. Response errors in establishment surveys with an example from an agribusiness survey: (n.d., accessed August 20, 2013 ).

33. Depoy E and Gitlin LN. Introduction to research: Understanding and applying multiple strategies, 3rd ed. St. Louis, MD: Elsevier Mosby, 2005.

34. Law M, Cooper B, Strong S, Stewart D, Rigby $P$ and L L. The Person-Environment-Occupation Model: $A$ transactive approach to occupational performance. Canadian Journal of Occupational Therapy. 1996; 63: 9-23.
35. Pierce D. Occupation by Design: Building therapeutic power. Philadelphia: FA Davis, 2003.

36. Christiansen C. Defining lives: occupation as identity: an essay on competence, coherence, and the creation of meaning. American Journal of Occupational Therapy. 1999; 53: 547-58.

37. Rocha E, Marche T and Briere J. The effect of forced-choice questions on children's suggestibility: a comparison of multiple choice questions and yes/no questions. Canadian Journal of Behavioural Science. 20I2); 45: I-II.

38. Cozby P. Methods in behavioural research, 9th ed. USA: McGrawHill Companies, 2005.

39. Health Professions Council of South Africa (HPCSA). Regulations relating to the registration of occupational therapy students and the minimum standards for the training of occupational therapy students: 2003.

\section{ACKNOWLEDGEMENTS}

Acknowledgements to the expert panel (Madeleine Duncan, Matthew Molineux, Mapheyeledi Motimele, David Nelson, Nicholas Pollard, Elelwani Ramugondo, Clare Wilding) for feedback on the measurement tool.

http://dx.doi.org/ I0.I 7 I 59/23 I 0-3833/20 I 5/v45no I a I I

Corresponding author

Caryn Green

caryngreen74@gmail.com

\section{APPENDIX I : FIRST YEAR LEARNING OUTCOMES RELATED TO THE BASIC CONCEPTS OF HUMAN OCCUPATION AND ARTFORMS MODULES}

By the end of the course, students will be able to:

* Describe the concept of 'occupation' and begin to understand its dimensions.

* Discuss the experience of doing an occupation.

* Describe the role that environment plays in an occupation. 